\title{
Abnormal Metabolism of Shellfish Sterols in a Patient with Sitosterolemia and Xanthomatosis
}

\author{
Richard E. Gregg, William E. Connor," Don S. Lin, * and H. Bryan Brewer, Jr. \\ Molecular Disease Branch, National Heart, Lung, and Blood Institute, National Institutes of Health, \\ Bethesda, Maryland 20892; and *Division of Endocrinology, Metabolism and Nutrition, \\ Department of Medicine, University of Oregon Health Sciences Center, Portland, Oregon 97201
}

\begin{abstract}
Sitosterolemia and xanthomatosis together are a disease characterized by premature cardiovascular disease, and by elevated plasma concentrations of total sterols and of plant sterols, especially sitosterol which is hyperabsorbed. In order to determine whether this abnormal metabolism also involved other sterols, a patient with sitosterolemia was fed a diet high in shellfish that contain significant quantities of noncholesterol sterols, some of which are less well absorbed than cholesterol in humans. Compared with control subjects $(n=8)$, the sitosterolemic subject had an increased absorption of 22-dehydrocholesterol $\mathbf{( 7 1 . 5 \%}$ vs. $43.8 \pm 11.4 \%$, mean \pm SD), C-26 sterol (80.6\% vs. $49.3 \pm 11.4 \%$ ), brassicasterol (51.8\% vs. $4.8 \pm 4.2 \%)$, and $24-$ methylene cholesterol $(60.5 \%$ vs. $16.0 \pm 8.3 \%)$. This enhanced absorption was associated with an increased plasma total shellfish sterol level (13.1 mg/dl vs. 1.9 $\pm 0.7 \mathrm{mg} / \mathrm{dl}$ in normals). In the sitosterolemic subject, as in normals, the shellfish sterols were not preferentially concentrated in any lipoprotein class, and $50-65 \%$ of these sterols were in the esterified form in plasma. Bile acids and neutral sterols were quantitated in bile obtained by duodenal aspiration. The bile acid composition did not differ significantly in the sitosterolemic subject compared with the normal controls. The sitosterolemic subject, though, was unable to concentrate normally the neutral shellfish sterols in bile. The normal controls concentrated the shellfish sterols in bile $6.3 \pm 1.7$ fold relative to the plasma shellish sterol concentration whereas the study subject was only able to concentrate them 2.1-fold. We propose that sitosterolemia and xanthomatosis occur from a generalized abnormality in the usual ability of the gut mucosa and other tissues of the body to discriminate among many different sterols. This has important implications for the understanding of the pathophysiology of this disease and for therapeutic recommendations.
\end{abstract}

\section{Introduction}

Sitosterolemia and xanthomatosis together are a rare familial disease characterized by the development of xanthomas at an early age, premature cardiovascular disease, elevated plasma sterol concentrations with markedly elevated concentrations of plant sterols, and an increased absorption and decreased excretion of sitosterol (1-5). Campesterol, stigmasterol, avenasterol, cholestanol, sitostanol, and campestanol have been found, in

Address reprint requests to Dr. Gregg, Building 10, Room 7N117, National Institutes of Health, Bethesda, MD 20892. 1986.

Received for publication 28 June 1985 and in revised form 10 January

The Journal of Clinical Investigation, Inc.

Volume 77, June 1986, 1864-1872 addition to sitosterol, in the plasma of some or all of these patients (1-6). The family studies are most consistent with this disease being inherited as an autosomal recessive disorder (1-5), and the heterozygous subjects have been reported to have hyperapobetalipoproteinemia (4). Sitosterol differs from cholesterol by the presence of an ethyl group at carbon 24 of cholesterol. This change in the sterol structure results in a marked reduction in dietary sitosterol absorption, compared with dietary cholesterol, a preferential excretion of sitosterol in bile, and a sitosterol level of $<1 \%$ of total plasma sterols in normal humans (7). Sitosterolemia subjects have been shown to absorb 19-30\% of dietary sitosterol $(1-3,5)$, and sitosterol has comprised $8-26 \%$ of total plasma sterols (1-6). In addition, subjects with sitosterolemia have been shown to have a defect in the biliary excretion of sitosterol $(3,5)$.

Some of the potential sites for regulation of sterol absorption, transport, storage, and excretion include $(a)$ intraluminal solubilization of sterols by bile acids in the small intestine, $(b)$ a sterol recognition site on cell membranes, $(c)$ intracellular sterol carrier or binding proteins, $(d)$ acyl CoA:cholesterol acyltransferase $(\mathrm{ACAT})^{1}$ (EC 2.3.1.26), (e) neutral cholesteryl ester hydrolase (NCEH) (EC 3.1.1.13), and $(f)$ enzymes involved in bile acid synthesis. It is unknown whether one of these is the site of the molecular defect in sitosterolemia subjects. In addition to the site of the molecular defect in this disease, other unknown aspects include: $(a)$ Does the defect express itself in many different tissues in the body or involve only the gastrointestinal tract? $(b)$ Is the abnormality specific for sitosterol or is it more generalized to affect other plant and animal sterols?

Certain shellfish (clams, oysters, scallops) contain a number of sterols not normally found in human tissues (Fig. 1). These sterols include 22-dehydrocholesterol, brassicasterol, 22-trans24-norcholesta-5,22-dien-3 $\beta$-ol (C-26 sterol), and 24-methylene cholesterol, and they comprise $>50 \%$ of the total tissue sterols of these organisms (8). In order to ascertain the ability of subjects with sitosterolemia to absorb and excrete these sterols, and to gain further insights into the pathogenesis of this disease, the following studies were performed.

\section{Methods}

Experimental subjects. A 38-year-old woman with sitosterolemia and xanthomatosis who has been previously reported, participated in these experiments (2). The patient was initially diagnosed as having hyperbetalipoproteinemia, but in 1974 she was found to have sitosterolemia. Representative fasting plasma lipid and lipoprotein concentrations are indicated in Table I. She has subsequently been treated with a low fat, low sterol diet and cholestyramine, $4 \mathrm{~g}$, three times a day. This has nor-

1. Abbreviations used in this paper: ACAT, acyl CoA:cholesterol acyltransferase; C-26 sterol, 22-trans-24-norcholesta-5,22-dien-3- $\beta$ ol; NCEH, neutral cholesteryl ester hydrolase. 


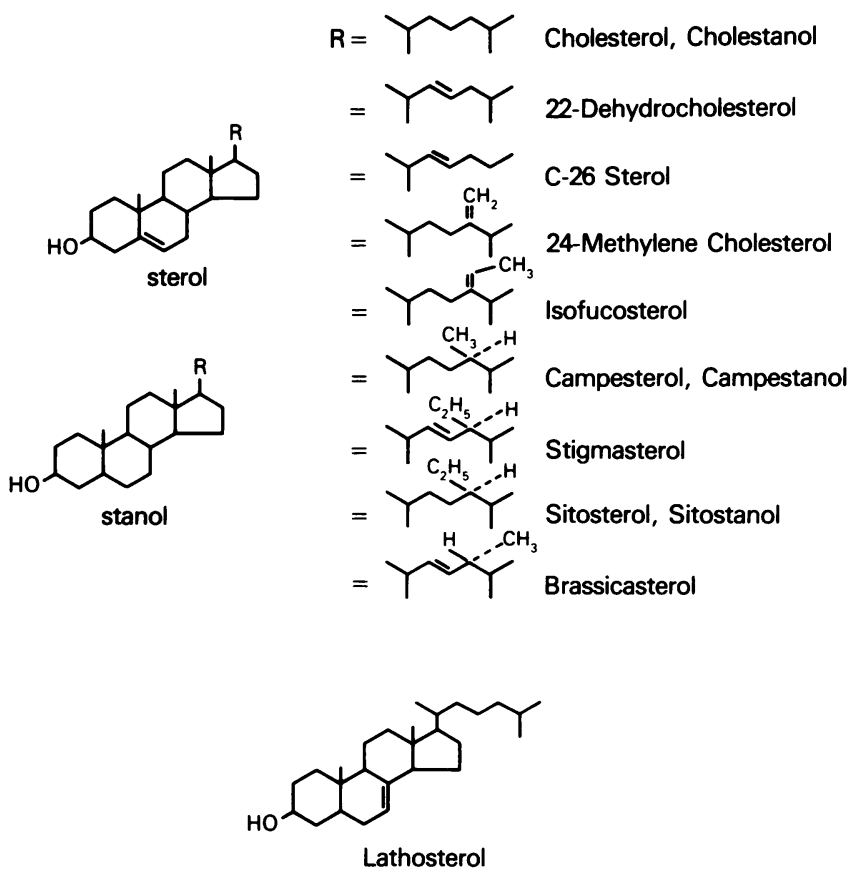

Figure 1. Chemical structures of the sterols quantitated in this investigation.

malized her total plasma sterol concentration, caused regression of her xanthalasma and had little change on her Achilles tendon xanthomas, which is consistent with a previous report of cholestyramine use in this disease (6). Because neomycin also inhibits the absorption of cholesterol $(9,10)$, she was given a trial of this drug. Cholestyramine was discontinued and neomycin, $1 \mathrm{~g}$, orally, twice a day was given for $3 \mathrm{wk}$, at which time it was discontinued because of nausea. This drug trial was associated with a $44 \%$ increase in total plasma sterols and suggests neomycin is of little use in treating these patients.

At the time of these investigations, she was $161 \mathrm{~cm}$ tall, weighed 66 $\mathrm{kg}$, and was healthy with no symptoms of cardiovascular disease. Her physical examination was significant for xanthalasma, thickened Achilles tendons, and an abdominal bruit. She was on no medications except for cholestyramine, $12 \mathrm{~g}$ per day, and this was discontinued $3 \mathrm{wk}$ prior to

Table I. Plasma Lipid and Lipoprotein Values in the Sitosterolemia Subject

\begin{tabular}{|c|c|c|c|c|c|}
\hline & \multirow{2}{*}{$\begin{array}{l}\text { Total } \\
\text { sterol }\end{array}$} & \multirow[b]{2}{*}{ Triglycerides } & \multicolumn{3}{|l|}{ Sterols } \\
\hline & & & VLDL & LDL & HDL \\
\hline & $m g / d l$ & $m g / d l$ & $m g / d l$ & $m g / d l$ & $m g / d l$ \\
\hline Off therapy & $287-355^{*}$ & $58-124$ & $9-26$ & $192-293$ & $46-69$ \\
\hline $\begin{array}{l}\text { (12 g per day) } \\
\text { Neomycin }\end{array}$ & $147-229 \ddagger$ & $69-126$ & $8-25$ & $86-132$ & $48-80$ \\
\hline $\begin{array}{l}\text { (2 g per day) } \\
\text { At the time of } \\
\text { shellish study } \\
\text { diet }\end{array}$ & 352 & 126 & 26 & 260 & 65 \\
\hline $\begin{array}{l}\text { At the time of } \\
\text { hysterectomy }\end{array}$ & 188 & 99 & 15 & 110 & 63 \\
\hline
\end{tabular}

* Range of six values.

¥ Range of 15 values. the study. Her baseline outpatient diet was high in carbohydrates and low in both animal and vegetable fat.

The clinical and biochemical characteristics and results of the normal control group have been previously reported $(11,12)$. The studies were performed using an approved protocol for human experimentation and informed consent was obtained from all subjects.

Shellfish feeding study. The subject was off medication and consuming a low fat diet (30\% fat) for 3 wk prior to admission. She was admitted to the National Institutes of Health and placed on an isocaloric diet rich in shellfish for $11 \mathrm{~d}$ with a composition of $35 \%$ fat, $36 \%$ carbohydrate, and $29 \%$ protein with a polyunsaturated to saturated fat ratio of 0.4 . She was fed exactly the same diet every day, and her weight was $66 \pm 1 \mathrm{~kg}$ during the course of the study. In order to measure the exact intake of different sterols, a total 1-d food aliquot was obtained for sterol analysis by the methods described in the "biochemical analysis" subsection. Her oral intake per day was $42 \mathrm{mg}$ of C-26 sterol, $90 \mathrm{mg}$ of 22-dehydrocholesterol, $123 \mathrm{mg}$ of brassicasterol, $89 \mathrm{mg}$ of 24-methylene cholesterol, and $182 \mathrm{mg}$ of cholesterol.

On days $0,1,4,7,9$, and 11 , blood was drawn after a 12 -h fast into glass tubes with a final concentration of $0.1 \%$ EDTA, the plasma was separated by low-speed centrifugation in a refrigerated centrifuge, and the lipoproteins were separated by ultracentrifugation (13).

On day 11 of the study, after a 12-h fast, a double lumen Anderson AN 20 nasogastric tube (H. W. Anderson Products, Inc., Oyster Bay, NY) was placed into the second portion of the duodenum and the placement was confirmed radiographically. Synthetic cholecystokinin (Kinevac, E. R. Squibb and Sons, Princeton, NJ) was injected intravenously $(4.2 \mu \mathrm{g})$, and bile was obtained by aspiration.

All feces were collected during the course of the shellfish feeding study. The plasma, lipoprotein, bile, and fecal samples were frozen at $-20^{\circ} \mathrm{C}$ until the sterol analyses were performed.

Measurement of tissue sterols. The patient underwent a hysterectomy in 1979 for menorrhagia while she was taking $8 \mathrm{~g}$ of cholestyramine per day for her elevated plasma sterol concentration. At the time of surgery samples of plasma, skin, adipose tissue, broad ligament, uterine artery, and uterine muscle were frozen in liquid nitrogen for analysis of sterols. Tissue lipids were extracted by chloroform and methanol (14). Sterols in both plasma and tissue lipid extracts were determined by the methods described below.

Biochemical analysis. For Table I, plasma cholesterol and triglyceride levels were quantitated on a Gilford System 3500 enzymatic analyzer

Table II. Retention Times of Sterols on Packed SE-30 and SP-1000 and Capillary SE-30 Gas Chromatographic Columns

\begin{tabular}{llll}
\hline & \multicolumn{3}{l}{ Relative retention time* } \\
\cline { 2 - 4 } Sterols & $\begin{array}{l}\text { Packed } \\
\text { SE-30 }\end{array}$ & $\begin{array}{l}\text { Packed } \\
\text { SP-1000 }\end{array}$ & $\begin{array}{l}\text { Capillary } \\
\text { SE-30 }\end{array}$ \\
\hline C-26 Sterol & 1.41 & 3.83 & 1.20 \\
22-Dehydrocholesterol & 2.10 & 5.61 & 1.53 \\
Cholesterol & 2.30 & 5.65 & 1.65 \\
Cholestanol & 2.30 & 5.93 & 1.68 \\
Brassicasterol & 2.57 & 6.34 & 1.80 \\
Lathosterol & 2.60 & 6.88 & 1.84 \\
24-methylene-cholesterol & 3.00 & 8.19 & 1.99 \\
Campesterol & 3.01 & 7.37 & 2.02 \\
Campestanol & 3.01 & - & 2.04 \\
Stigmasterol & 3.30 & 7.83 & 2.11 \\
Sitosterol & 3.80 & 9.06 & 2.37 \\
Sitostanol & 3.80 & - & 2.40 \\
Isofucosterol & - & 10.87 & - \\
\end{tabular}

$*$ Cholestane $=1.00$. 


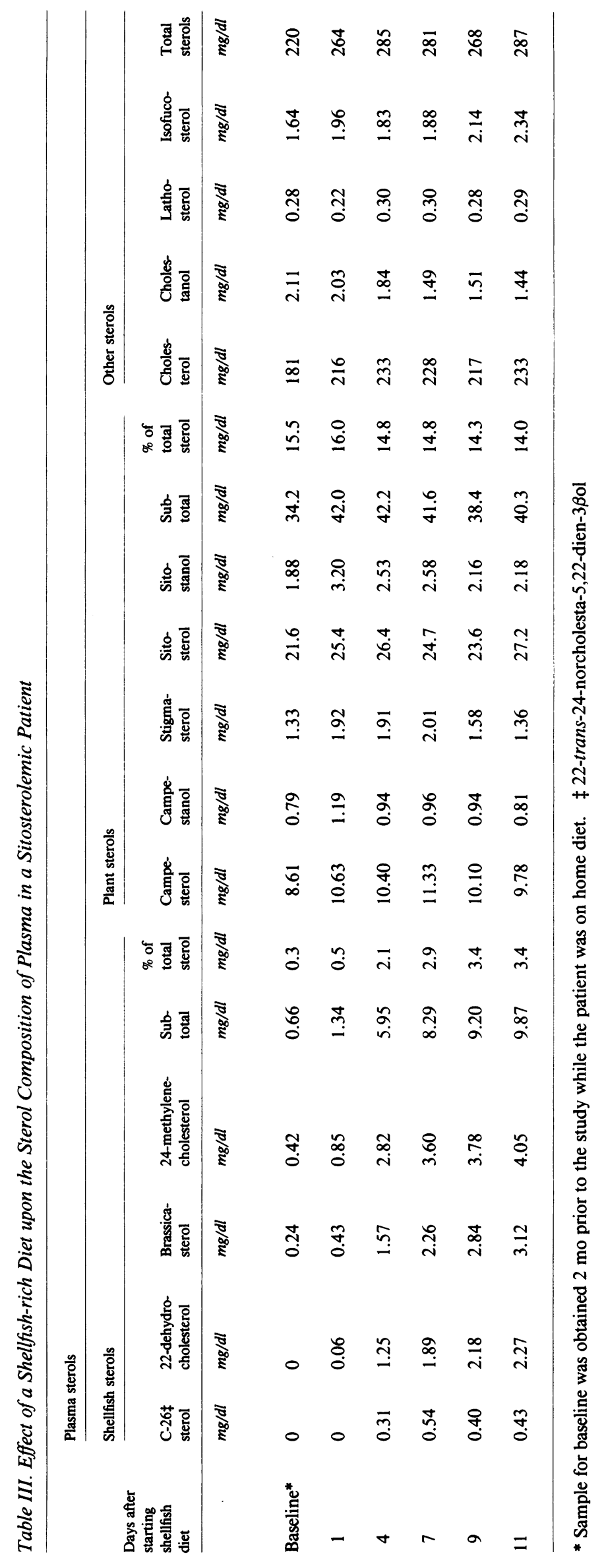

$1866 \quad$ R. E. Gregg, W. E. Connor, D. S. Lin, and H. B. Brewer, Jr. 


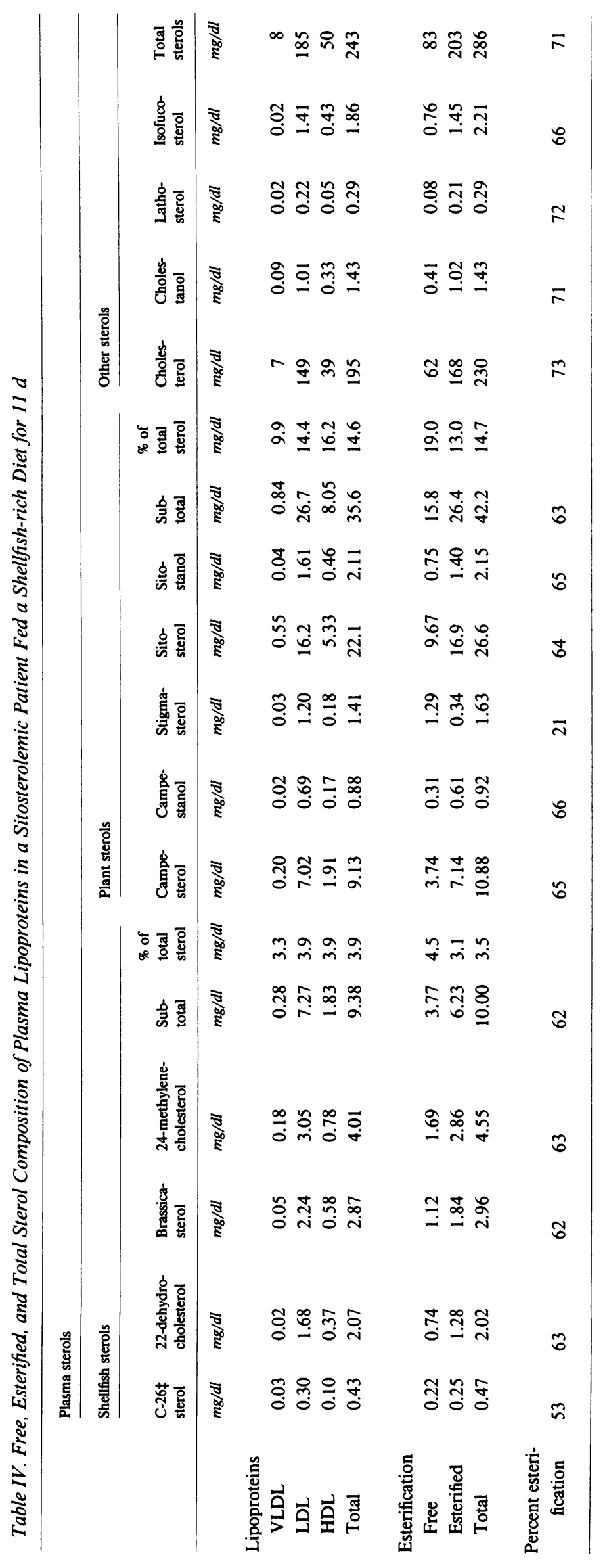


Table V. Comparison of Shellfish and Plant Sterols and Cholesterol in the Plasma of Normal Subjects and Sitosterolemic Patient Fed a Shellfish-rich Diet

\begin{tabular}{|c|c|c|c|c|c|c|c|c|c|c|}
\hline \multirow[b]{3}{*}{ Sterol form } & \multicolumn{5}{|c|}{ Plasma sterol composition } & & & & & \\
\hline & \multicolumn{5}{|l|}{ Shellfish sterols } & \multicolumn{4}{|l|}{ Plant sterols } & \multirow[b]{2}{*}{$\begin{array}{l}\text { Choles- } \\
\text { terol }\end{array}$} \\
\hline & C-26 sterol & $\begin{array}{l}\text { 22-dehydro- } \\
\text { cholesterol }\end{array}$ & $\begin{array}{l}\text { Brassica- } \\
\text { sterol }\end{array}$ & $\begin{array}{l}\text { 24-methylene } \\
\text { cholesterol }\end{array}$ & Subtotal & Campesterol & $\begin{array}{l}\text { Stigma- } \\
\text { sterol }\end{array}$ & Sitosterol & Subtotal & \\
\hline & $m g / d l$ & $m g / d l$ & $m g / d l$ & $m g / d l$ & $m g / d l$ & $m g / d l$ & $m g / d l$ & $m g / d l$ & $m g / d l$ & $m g / d l$ \\
\hline Sitosterolemia & 0.43 & 2.27 & 3.12 & 4.05 & 9.87 & 9.78 & 1.36 & 27.20 & 38.34 & 233 \\
\hline Normals* & $0.15 \pm 0.06 \S$ & $0.49 \pm 0.28$ & 0 & $1.12 \pm 0.47$ & $1.76 \pm 0.70$ & 0 & 0 & $0.15 \pm 0.11$ & $0.15 \pm 0.11$ & $180 \pm 32$ \\
\hline Normalsł & $0.16 \pm 0.03$ & $0.57 \pm 0.20$ & $0.14 \pm 0.17$ & $0.53 \pm 0.22$ & $1.40 \pm 0.50$ & $0.04 \pm 0.04$ & 0 & $0.13 \pm 0.06$ & $0.17 \pm 0.06$ & $157 \pm 31$ \\
\hline
\end{tabular}

* Eight subjects from Connor and Lin (11). ¥ Seven subjects from Lin et al. (12). § Mean \pm SD.

and high density lipoprotein (HDL) cholesterol was determined in plasma after dextran sulfate precipitation (15). The lipoprotein cholesterol analyses were performed according to the Lipid Research Clinics methods (16). In all other tables, the lipids were quantitated as described below.

The neutral sterol content of the diet, plasma, bile, and stool was analyzed by the methods described in detail previously $(11,17)$. Briefly, they involved saponification, extraction, digitonin precipitation, thinlayer and gas-liquid chromatography, and mass spectrometry. Authentic standards of the sterols were used for calibration. For separating the complex shellfish sterols, an additional gas-liquid chromatography column with SP-1000 packing was used, thus enabling the separation of brassicasterol from lathosterol, campesterol from 24-methylene cholesterol, and sitosterol from isofucosterol (18). Cholestanol was separated from other sterols by argentation thin-layer chromatography and quantified by gas-liquid chromatography with a QF-1 column (19). Plasma free and esterified sterols were separated by thin-layer chromatography before quantitation (20). For comparison, plasma and bile neutral sterols were also analyzed by a gas-liquid chromatograph equipped with glass capillary column (SE-30, $30 \mathrm{~m})(21)$. The retention times of the sterols on the different columns are given in Table II. The results of the two methods were very similar. We have utilized the capillary column data in this report.

The bile acids were analyzed by the methods previously described (22). Samples were subjected to saponification, extraction, methylation, and thin-layer chromatography. The bile acids were converted to trifluoroacetate derivatives and determined by gas-liquid chromatography with a QF-1 column.

\section{Results}

In order to determine whether the defect in sterol absorption in patients with sitosterolemia was restricted to plant sterols, we investigated the absorption of shellfish sterols in a sitosterolemia patient. The patient was fed a diet very high in shellfish, and Table III shows the changes in plasma shellfish sterols and plant sterols over time with this diet. The shellfish sterols increased 11 -fold while the plant sterols and cholesterol increased $18 \%$ and $29 \%$, respectively. In addition, the baseline concentrations of the $5 \alpha$-saturated sterols, cholestanol, campestanol and sitostanol were increased in the plasma, as has been recently reported (6). The baseline isofucosterol concentration was also increased while lathosterol is normally present at this concentration. The $5 \alpha$-saturated forms of the shellfish sterols were not detected. The shellfish sterols were evenly distributed in the plasma lipoprotein density subfractions (Table IV). Plasma shellfish sterols were also esterified approximately to the same degree as the other sterols (Table IV). Table V compares the plasma sterol levels in the subject with sitosterolemia with normal subjects previously reported by us $(11,12)$. While on comparable diets, the sitosterolemic subject had plasma shellfish sterol levels 6 times normal, plant sterol levels 200 times normal, and cholesterol levels 1.4 times normal.

Shellfish sterol absorption. The subject was on a defined diet high in shellfish and the shellfish sterol absorption was determined by the difference between sterol intake and sterol excretion in the feces assuming that hepatic reexcretion of these sterols was negligible compared with the dietary intake. The absorption of the shellfish sterols is shown in Fig. 2 and compared with shellfish sterol absorption in normal subjects. The absorption of C-26 sterol and 22-dehydrocholesterol are $\sim 2$ times normal whereas 24-methylene cholesterol is 4-5 times normal and brassicasterol is $8-10$ times normal. Therefore, the subject with sitosterolemia hyperabsorbed all of the shellfish sterols quantitated.

Bile acid and neutral sterols in bile. At the completion of the shellfish sterol feeding study, bile samples were obtained from the study subject. The different acidic and neutral sterols in the bile were quantitated (Tables VI and VII) and compared

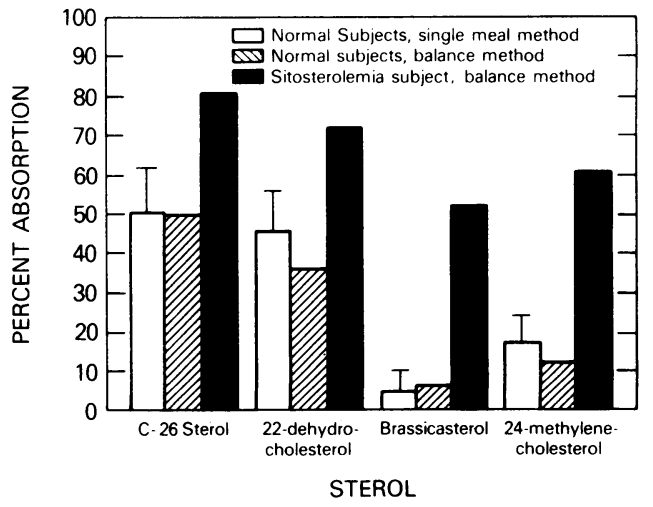

Figure 2. Absorption of shellfish sterols by sitosterolemic and normal subjects while consuming a diet enriched with shellfish. The absorption of exogenous dietary sterols was quantitated by two different methods for normals. The first method (single-meal method) is represented by the open bar $(\square)$, and the error bars are \pm 1 SD for eight subjects (11). The second method (sterol balance method) is represented by the cross-hatched bar $(\square)$ and is the mean of two subjects (11). The sterol absorption in the sitosterolemia subject was also quantitated by the sterol balance method and is represented by the solid bars $(\square)$ 
Table VI. Bile Acid Composition of Bile in Sitosterolemia and Normal Subjects While on a Shellfish-rich Diet

\begin{tabular}{|c|c|c|c|c|c|c|c|c|c|}
\hline \multirow[b]{2}{*}{ Subject } & \multicolumn{8}{|c|}{ Bile acid composition } & \multirow[b]{2}{*}{$\begin{array}{l}\text { Bile acid } \\
\text { content }\end{array}$} \\
\hline & Lithocholic & $\begin{array}{l}3 \beta, 12 \alpha \\
\text { dihydroxy- } \\
\text { cholanic }\end{array}$ & Deoxycholic & $\begin{array}{l}\text { Chenode- } \\
\text { oxycholic }\end{array}$ & $\begin{array}{l}\text { Ursodeoxy- } \\
\text { cholic }\end{array}$ & Cholic & $\begin{array}{l}3 \alpha, \text { hydroxy- } \\
12 \text { keto } \\
\text { cholanic }\end{array}$ & Unidentified & \\
\hline & \% of total & \% of total & $\%$ of total & $\%$ of total & \% of total & $\%$ of total & $\%$ of total & \% of total & $\mu \mathrm{g} / \mathrm{ml}$ bile \\
\hline Sitosterolemia & 3.4 & 1.4 & 37.2 & 24.0 & 1.2 & 29.4 & 3.0 & 0.4 & 13,200 \\
\hline Normal* $^{*}$ & $3.7 \pm 1.2 \ddagger$ & $0.8 \pm 0.6$ & $27.2 \pm 16.4$ & $21.0 \pm 6.5$ & $0.3 \pm 0.6$ & $45.4 \pm 12.8$ & $0.9 \pm 1.7$ & $0.7 \pm 0.7$ & $13,724 \pm 9,238$ \\
\hline
\end{tabular}

* Seven subjects from Lin et al. (12). $¥$ Mean \pm SD.

with the bile composition of normal subjects while on a comparable high shellfish sterol diet. The bile acids in the sitosterolemic subject were slightly enriched in deoxycholic acid and relatively poor in cholic acid, though these values were still within the normal range. There were minimal differences in the other bile acids (Table VI). The fraction of total biliary sterols that was shellfish sterols was slightly higher in the study subject than in the control subjects (Table VII), but this difference was not nearly as great as the difference between these subjects for plasma shellfish sterols (Table V).

Table VII also compares the ratio of the relative concentrations of each of the neutral shellfish sterols in bile with their relative concentration in plasma in normals and the sitosterolemic subject. The higher the ratio indicates the greater the ability of the liver to concentrate that sterol in bile in comparison with the other sterols. In normal subjects the relative concentration of biliary shellfish sterols and plant sterols were 6.3- and 25.8fold greater than in plasma. In the sitosterolemic subject, however, the relative concentrations of biliary shellfish and plant sterols were only 2.1 and 0.7 of the relative concentration in plasma. Thus, in addition to hyperabsorption of shellfish sterols, the sitosterolemic subject had a relative inability to concentrate these sterols in bile. Both of these abnormalities would be expected to result in an elevation of the plasma shellfish sterol concentration.

Tissue sterol content. This patient had menorrhagia and had a hysterectomy performed. The surgery was performed from an abdominal approach and samples of different tissues were obtained for identification and quantification of sterols; the stanols were not analyzed in these samples. Table VIII shows that all tissues had substantial concentrations of plant sterols.

\section{Discussion}

Patients with sitosterolemia and xanthomatosis have an abnormality in plant sterol metabolism leading to elevated plasma plant sterol levels, tendinous xanthomas, and premature atherosclerosis (1-6). To gain further insights into sterol metabolism in sitosterolemic subjects, we studied the metabolism of shellfish sterols in an individual with sitosterolemia.

Normal individuals absorb shellfish sterols and the percentage of absorption is dependent upon the structure of the particular sterol in question, e.g., the sterols that resemble cholesterol the closest (the C-26 sterol and 22-dehydrocholesterol, having 26 or 27 carbons and no side chain at carbon 24) are absorbed in the range of $40 \%$ of the ingested amount as is cholesterol. On the other hand, the sterols that resemble plant sterols (brassicasterol and 24-methylene-cholesterol, sterols with 28 or 29 carbons and a side chain at C-24) are absorbed $\sim 10 \%$. The patient with sitosterolemia hyperabsorbs all sterols. 22-dehydrocholesterol and the C-26 sterol are absorbed $>70 \%$ while brassicasterol and 24 methylene-cholesterol are absorbed $>50 \%$. In addition, we have found that the absorption of cholesterol is in the high normal

Table VII. Comparison of Shellfish and Plant Sterols and Cholesterol in the Bile and the Ratio of Bile Sterols to Plasma Sterols in Normal Subjects and a Sitosterolemia Patient Fed a Shellfish-rich Diet

\begin{tabular}{|c|c|c|c|c|c|c|c|c|c|c|}
\hline \multirow[b]{2}{*}{ Subjects } & \multicolumn{5}{|c|}{ Shellfish sterols } & \multicolumn{4}{|l|}{ Plant sterols } & \multirow[b]{2}{*}{$\begin{array}{l}\text { Choles- } \\
\text { terol }\end{array}$} \\
\hline & C-26 sterol & $\begin{array}{l}\text { 22-dehydro- } \\
\text { cholesterol }\end{array}$ & $\begin{array}{l}\text { Brassica- } \\
\text { sterol }\end{array}$ & $\begin{array}{l}\text { 24-methylene- } \\
\text { cholesterol }\end{array}$ & Subtotal & $\begin{array}{l}\text { Campes- } \\
\text { terol }\end{array}$ & $\begin{array}{l}\text { Stigma- } \\
\text { sterol }\end{array}$ & Sitosterol & Subtotal & \\
\hline Sterol composition & \multicolumn{10}{|l|}{$\%$ of total } \\
\hline Sitosterolemia & 0.61 & 1.41 & 1.85 & 3.05 & 6.92 & 3.42 & 0.98 & 5.22 & 9.62 & 78.9 \\
\hline Normals* & $0.44 \pm 0.12 \ddagger$ & $0.50 \pm 0.13$ & $0.76 \pm 0.20$ & $3.00 \pm 1.06$ & $5.01 \pm 1.22$ & $1.06 \pm 0.07$ & $0.06 \pm 0.07$ & $1.18 \pm 0.42$ & $2.29 \pm 0.74$ & $90.4 \pm 2.2$ \\
\hline \multicolumn{11}{|c|}{ Sterol ratio (bile/plasma) } \\
\hline Sitosterolemia & 4.3 & 1.9 & 1.8 & 2.2 & 2.1 & 1.0 & 2.2 & 0.6 & 0.8 & ND \\
\hline Normals*§ & $4.8 \pm 1.1$ & $2.6 \pm 0.7$ & $39.1 \pm 38.4$ & $10.0 \pm 2.9$ & $6.3 \pm 1.7$ & $64.5 \pm 51.2$ & ND & $17.0 \pm 8.8$ & $25.8 \pm 13.1$ & ND \\
\hline
\end{tabular}

ND, not determined. * Seven subjects from Lin et al. (12). ¥ Mean \pm SD. $\S$ These ratios were calculated by taking the ratio of a given sterol to cholesterol in bile divided by the same ratio in blood. This approach must be followed because of the invariable and inconsistent dilution of bile samples by gastric and intestinal secre-
tions. 


\begin{tabular}{|c|c|c|c|c|c|c|c|}
\hline \multirow[b]{3}{*}{ Plasma or tissue } & \multicolumn{7}{|c|}{ Sterol content in plasma and tissue (wet weight) } \\
\hline & \multicolumn{5}{|l|}{ Plant sterols } & \multirow[b]{2}{*}{ Cholesterol } & \multirow[b]{2}{*}{ Total sterol } \\
\hline & Campesterol & Stigmasterol & Sitosterol & Total & $\%$ total sterol & & \\
\hline Plasma $(m g / d l)$ & 8.6 & 1.3 & 23.1 & 33.0 & 15.8 & 176 & 209 \\
\hline Skin $(m g / g)$ & 0.040 & 0 & 0.091 & 0.131 & 6.6 & 1.87 & 2.00 \\
\hline Subcutaneous fat $(m g / g)$ & 0.002 & 0 & 0.044 & 0.046 & 5.0 & 0.88 & 0.92 \\
\hline Uterus $(m g / g)$ & 0.351 & 0.072 & 0.773 & 1.196 & 15.8 & 6.37 & 7.56 \\
\hline Uterine artery $(m g / g)$ & 0.194 & 0.014 & 0.481 & 0.689 & 12.6 & 4.76 & 5.45 \\
\hline Broad ligament $(m g / g)$ & 0.705 & 0 & 1.970 & 2.675 & 10.5 & 22.8 & 25.5 \\
\hline
\end{tabular}

range (data not shown). Thus, the sitosterolemic individual had an increased absorption of all the sterols evaluated.

Abnormalities in the liver metabolism of sterols were also observed in the sitosterolemic patient. The level of plant sterols in plasma in normal individuals is kept low by at least two mechanisms. The first is the relatively poor absorption of dietary plant sterols (7). The second mechanism involves the ability of the liver to excrete plant sterols preferentially in relationship to cholesterol. Salen et al. (7) found that the half-life of sitosterol was much shorter than cholesterol. In a recent study, we reported that both shellfish and plant sterols are selectively concentrated in normal bile (12). These two pieces of evidence suggest the preferential hepatic excretion of both shellfish and plant sterols in normal subjects. In contrast, our subject with sitosterolemia had an inability to concentrate shellfish and plant sterols normally in bile. This extends the previous finding that sitosterolemia subjects do not concentrate sitosterol normally in bile (3, 5). The present results have shown that this subject with sitosterolemia has a generalized hyperabsorption of dietary sterols, and in addition, the liver is unable to concentrate plant and shellfish sterols normally in bile, leading to elevated plasma concentrations of these sterols.

The mechanism for the development of xanthomas and premature atherosclerosis is more elusive. The composition of the sterols in the different tissues evaluated was similar to the plasma sterol composition with cholesterol being the predominant sterol (Table VII). Therefore, the tissues did not solely accumulate abnormal sterols. This is similar to the sterol composition in xanthomas from these subjects $(1,2)$. It is not possible from these data to discern between the abnormal sterols directly disrupting normal intracellular sterol homeostasis leading to xanthoma formation versus all tissues having a molecular defect in the metabolism of sterols leading to a generalized accumulation of many different sterols in these tissues.

The site(s) at which the cells determine the specificity for sterol metabolism is (are) as yet unknown. Sterols are either directly synthesized from acetyl-CoA or absorbed in the gastrointestinal tract from dietary sterols. The ingested dietary sterols are solubilized by bile acids, absorbed across the intestinal mucosal cell membrane (23), and transported in the cytoplasm by sterol carrier or binding proteins $(24,25)$. Once in the cell, they either remain as free sterols or are esterified with long-chain fatty acids $(26,27)$. If they remain as free sterols, they are poorly absorbed into the body $(28,29)$, and presumably remain within the cell which is then sloughed into the intestinal lumen and excreted in the feces (24). If the sterols are esterified they may be incorporated into chylomicrons and secreted into the lymphatics eventually reaching the intravascular space (26-29). The amount of intracellular free sterol and sterol ester is determined by the rate of esterification by ACAT and the rate of sterol ester hydrolysis by NCEH. Within the liver, sterols may remain as free sterols or be esterified by ACAT. If they remain as free sterols, they may be excreted into the bile either as free sterols or as bile acids after further metabolism $(30,31)$. If the sterols are esterified with fatty acids, they are no longer available for secretion into bile. The fate of sterol esters in liver is not clearly known. Some may be incorporated into very low density lipoproteins (VLDL) and secreted, but most are subsequently hydrolyzed to free sterols. It is not known at the present time whether these newly hydrolyzed sterols are in free equilibrium with all free sterols in hepatocytes, or if they contribute to certain metabolic pools, such as the free sterols in nascent VLDL and cellular membranes, and not to other pools, such as biliary sterols and bile acids. There is evidence, though, for metabolic compartments of free sterols within hepatocytes that are not in equilibrium with other intercellular free sterol pools (31). As in intestinal mucosal cells and hepatocytes, sterols may exist in other tissues as free sterols or sterol esters. If they remain as free sterols, they may be transported to and incorporated into the cytoplasmic membrane where they are removed by HDL by reverse cholesterol transport (32). If they are esterified, they form nonmembrane-bound lipid droplets and are stored as the ester (33).

A unifying hypothesis for the abnormality in this subject with sitosterolemia is that the discrimination for esterification of the different sterols is lost, and that the equilibrium is shifted in the direction of more esterification of sterols. There are multiple possible sites for the recognition of structurally different sterols and control of sterol esterification including solubilization of sterols in the intestine, a sterol recognition site on plasma membranes, sterol carrier proteins, ACAT, and NCEH. ACAT is a particularly good candidate for this function with the recent observation that ACAT is able to discriminate between cholesterol and sitosterol when catalyzing the esterification of sterols in rat hepatocytes (34) and rabbit intestinal mucosal cells (35).

The lack of specificity in intracellular esterification of sterols leading to increased intercellular sterol esters could result in the following phenomena: First, the esterification of sterols is important for the incorporation of sterols into intestinal chylomicrons; therefore increased mucosal esterification of sterols could result in increased sterol absorption (26-29). Secondly, the tissue storage form of sterols is the esterified sterol (33), whereas the free sterol is metabolically active and involved in 
reverse cholesterol transport via HDL (32). Therefore, if there is increased intracellular sterol esterification, there may be decreased intracellular free sterol concentrations that could lead to up regulation of cholesterol synthesis and increased endocytosis of sterol containing lipoproteins (36) with a decreased transport of free sterols out of cells on HDL (32). This could cause increased tissue stores of sterol esters, xanthoma formation, and premature atherosclerosis. Thirdly, it is the pool of free sterols in the liver that is utilized for the secretion of sterols into bile $(30,31)$. If a particular sterol is not esterified, there may be preferential excretion of that sterol into bile, as is observed in normal subjects for sitosterol and shellfish sterols. If the sterols are esterified, they are no longer available for secretion into bile. Some of the sterol esters may be either secreted as esters in newly formed lipoprotein particles (31) or stored as esters, but most of them are hydrolyzed to free sterols by NCEH. There is evidence for distinct intracellular metabolic pools of sterols in hepatocytes, but it is not known which pool(s) the newly hydrolyzed sterols contribute to or if they are in equilibrium with all the pools (31). It is possible that the hydrolyzed free sterols contribute to the membrane sterol-lipoprotein particle sterol pool and not to the biliary sterol-bile acid pool. Therefore, if there were an increased esterification of sterols, they could be diverted from the biliary sterol pool into the sterol ester and the cellular membrane/lipoprotein sterol pools with a concomitant decrease in the biliary excretion of these sterols.

These results have important implications for the therapy of this disease. First, the metabolic abnormality in this disease involves sterols in general, not just plant sterols. Therefore, patients should be treated with a low total-sterol diet, rather than with just the avoidance of plant sterols. Secondly, it has been our experience that this patient responds to cholestyramine therapy and not to neomycin. Therefore, because of the occurrence of markedly premature cardiovascular disease in these subjects, a low fat diet with cholestyramine drug therapy would seem to be the most appropriate initial therapy at the present time.

This disease has been called by various names by different investigators. Initially it was called $\beta$-sitosterolemia and xanthomatosis $(1,2)$ and subsequently phytosterolemia (3-5), and most recently sitosterolemia and xanthomatosis (6). We have now shown that this abnormality in sterol metabolism extends to shellfish sterols, and by inference, is probably a general abnormality in sterol recognition. We, therefore, feel that this disease should be called sitosterolemia and xanthomatosis, at least until the defect is known at a molecular level, for the following reasons: First, because there is no $\alpha$-sitosterol, the $\beta$ prefix is unnecessary. Secondly, other investigators have called the disease phytosterolemia to indicate there as an increased plasma level of multiple plant sterols, not just sitosterol. Now we have shown that this abnormality extends to other animal sterols and is not limited to just plant sterols. Therefore, phytosterolemia also does not adequately describe this disease. Rather than propose a new name, such as hypersterolemia, we would suggest that this disease be named after the predominant abnormal sterol found in plasma, sitosterol, until the defect is understood at a molecular level, at which time a new name based on this abnormality can be given.

In conclusion, we have presented evidence for a generalized abnormality in the metabolism of multiple sterols in tissues of the body in a sitosterolemic subject. In addition, we have proposed that this abnormality may involve a defect in the metab- olism of sterol esters leading to an increased intracellular esterification of sterols and a relative loss of discrimination between different sterols. The site for the defect in sterol recognition is as yet unknown.

\section{Acknowledgments}

We would like to thank Mrs. Imogene Surrey for preparation of the manuscript. In addition, we would like to thank Mrs. Patti Riggs and the dietary staff at the Clinical Center of the National Institutes of Health for helping with the diet portion of this study.

\section{References}

1. Bhattacharyya, A. K., and W. E. Connor. 1974. $\beta$-Sitosterolemia and xanthomatosis: a newly described lipid storage disease in two sisters. J. Clin. Invest. 53:1033-1043.

2. Schulman, R. S., A. K. Bhattacharyya, W. E. Connor, and D. S. Fredrickson. 1976. $\beta$-Sitosterolemia and xanthomatosis. N. Engl. J. Med. 294:482-483.

3. Miettinen, T. A. 1980. Phytosterolemia, xanthomatosis and premature atherosclerotic arterial disease: a case with high plant sterol absorption, impaired sterol elimination and low cholesterol synthesis. Eur. J. Clin. Invest. 10:27-35.

4. Kwiterovich, P. O., Jr., P. S. Bachorik, H. H. Smith, V. A. McKusick, W. E. Connor, B. Teng, and A. D. Sniderman. 1981. Hyperapobetalipoproteinemia in two families with xanthomatosis and phytosterolemia. Lancet. $i: 466-469$.

5. Lin, H.-J., C. Wang, G. Salen, K-C. Lam, and T-K. Chan. 1983. Sitosterol and cholesterol metabolism in a patient with coexisting phylosterolemia and cholestanolemia. Metab. Clin. Exp. 32:126-133.

6. Salen, G., P. O. Kwiterovich, S. Shefer, G. S. Tint, I. Horak, V. Shore, B. Dayal, and E. Horak. 1985. Increased plasma cholestanol and $5 \alpha$-saturated plant sterol derivatives in subjects with sitosterolemia and xanthomatosis. J. Lipid Res. 26:203-209.

7. Salen, G., E. H. Ahrens, and S. M. Grundy. 1970. Metabolism of $\beta$-sitosterol in man. J. Clin. Invest. 49:952-967.

8. Connor, W. E., and D. S. Lin. 1982. The effect of shellfish in the diet upon the plasma lipid levels in humans. Metab. Clin. Exp. 31:10461051.

9. Sedaghat, A., P. Samuel, J. R. Crouse, and E. H. Ahrens, Jr. 1975. Effects of neomycin on absorption, synthesis, and/or flux of cholesterol in man. J. Clin. Invest. 55:12-21.

10. Miettinen, T. A. Effect of neomycin alone and in combination with cholestyramine on serum cholesterol and fecal steroids in hypercholesterolemic subjects. J. Clin. Invest. 64:1485-1493.

11. Connor, W. E., and D. S. Lin. 1981. Absorption and transport of shellfish sterols in human subjects. Gastroenterology. 81:276-284.

12. Lin, D. S., W. E. Connor, and B. E. Phyllipson. 1984. Sterol composition of normal human bile, effect of feeding shellish (marine) sterols. Gastroenterology. 86:611-617.

13. Havel, R. J., H. A. Eder, and J. H. Bragdon. 1955. The distribution and chemical composition of ultracentrifugally separated lipoproteins in human serum. J. Clin. Invest. 34:1345-1353.

14. Folch, J., M. Lees, and G. H. Sloane-Stanley. 1957. A simple method for the isolation and purification of total lipids from animal tissues. J. Biol. Chem. 226:497-509.

15. Warnick, G. R., J. Benderson, J. J. Albers, E. E. Baillie, B. Sexton, E. J. Schaefer, D. Carlson, M. Hill, H. B. Brewer, Jr., D. A. Wiebe, J. Hazlehurst, and G. R. Cooper. 1982. Dextran sulfate-magnesium precipitation procedure for quantitation of high density lipoprotein cholesterol. Clin. Chem. 28:1379-1388.

16. Lipid Research Clinics Program. 1974. Manual of Laboratory Operations. DHEW publication No. NIH 75-628, National Heart and Lung Institute, Bethesda, MD.

17. Connor, W. E., D. T. Witiak, D. B. Stone, and M. L. Armstrong. 1969. Cholesterol balance and fecal neutral steroid and bile excretion in 
normal men fed dietary fats of different fatty acid composition. J. Clin. Invest. 48:1363-1375.

18. Nordby, H. E., and S. Nagy. 1973. An evaluation of recent gasliquid chromatographic liquid phases for resolution of acetylated plant sterols. J. Chromatogr. 73:187-193.

19. Ilias, A. M., W. E. Connor, H. T. Cory, D. S. Lin, G. D. Daves, Jr., and W. W. Krippaehne. 1980. Sterols of human gallstones: the recent identification of eight different digitonin precipitable sterols. Gastroenterology. 79:539-544.

20. Connor, W. E., and D. S. Lin. 1977. Placental transfer of cholesterol-4-C $\mathrm{C}^{14}$ into rabbit and guinea pig fetus. J. Lipid Res. 8:558-564.

21. Lin, D. S., A. M. Ilias, W. E. Connor, R. S. Caldwell, H. T. Cory, and G. D. Daves, Jr. 1982. Composition and biosynthesis of sterols in selected marine phytoplankton. Lipids. 17:818-824.

22. Lin, D. S., W. E. Connor, L. K. Napton, and R. F. Heizer. 1978. The steroids of 2000-year-old human coprolites. J. Lipid Res. 19:215221.

23. Thomson, A. B. R. 1978. Intestinal absorption of lipids: influence of the unstirred water layer and bile acid micelle. In Disturbances in Lipids and Lipoprotein Metabolism. J. M. Dietschy, A. M. Gotto, Jr., and J. A. Ontko, eds. American Physiological Society, Bethesda, MD. 29-55.

24. Dempsey, M. E., K. E. McCoy, H. N. Baker, A. DimitriadouVafiadou, T. Lorsbach, and J. B. Howard. 1981. Large scale purification and structural characterization of squalene and sterol carrier protein. $J$. Biol. Chem. 256:1867-1873.

25. Noland, B. J., R. E. Arebalo, E. Hansbury, and T. J. Scallen. 1980. Purification and properties of sterol carrier protein 2. J. Biol. Chem. 255:4282-4289.

26. Gallo, L. L., T. Newbill, J. Hyun, G. V. Vahouny, and C. R. Treadwell. 1977. Role of pancreatic chosterol esterase in the uptake and esterification of cholesterol by isolated intestinal cells. Proc. Soc. Exp. Biol. Med. 156:277-281.
27. Norum, K. R., A. C. Lilljequist, P. Helgerud, E. R. Norum, A. Mo, and B. Selbehk. 1979. Esterification of cholesterol in human small intestine: The importance of acyl-CoA:cholesterol acyltransferase. Eur. J. Clin. Invest. 9:55-62.

28. Heider, J. G., C. E. Pickens, and L. A. Kelly. 1983. Role of acylCoA: cholesterol acyltransferase in cholesterol absorption and its inhibition by 57-118 in the rabbit. J. Lipid Res. 24:1127-1134.

29. Bennett Clark, S., and A. M. Tercyak. 1984. Reduced cholesterol transmucosal transport in rats with inhibited mucosal acyl-CoA: cholesterol acyltransferase and normal pancreatic function. J. Lipid Res. 25:148-159.

30. Grundy, S. M., and A. L. Metzger. 1972. A physiological method for estimation of hepatic secretion of biliary lipids in man. Gastroenterology. 62:1200-1217.

31. Turley, S. D., and J. M. Dietschy. 1981. The contribution of newly synthesized cholesterol to biliary cholesterol in the rat. J. Biol. Chem. 256:2438-2446.

32. Glomset, J. A. 1980. High density lipoproteins in human health and disease. Adv. Intern. Med. 25:91-116.

33. Rapp, J. H., W. E. Connor, D. S. Lin, T. Inahara, and J. M. Porter. 1983. Lipids of human atherosclerotic plaques and xanthomas: clues to the mechanism of plaque progression. J. Lipid Res. 24:13291335.

34. Tavani, D., W. R. Nes, and J. T. Bilheimer. 1982. The sterol substrate specificity of acyl CoA: cholesterol acyltransferase from rat liver. J. Lipid Res. 23:774-781.

35. Field, F. J., and S. N. Mathus. $\beta$-sitosterol: esterification by intestinal acylcoenzyme A: cholesterol acyltransferase (ACAT) and its effect on cholesterol esterification. J. Lipid Res. 24:409-417.

36. Brown, M. S., and J. L. Goldstein. A general scheme for the regulation of cholesterol metabolism in mammalian cells. In Disturbances in Lipid and Lipoprotein Metabolism. J. M. Dietschy, A. M. Gotto, Jr., and J. A. Ontko, eds. American Physiological Society, Bethesda, MD. 173-180. 